\title{
Infrared Radiation Assisted Stokes' Law Based Synthesis and Optical Characterization of ZnS Nanoparticles
}

\author{
Beer Pal Singh, ${ }^{1}$ Ravish Kumar Upadhyay, ${ }^{1}$ Rakesh Kumar, \\ Kamna Yadav, ${ }^{2}$ and Hector I. Areizaga-Martinez ${ }^{3}$ \\ ${ }^{1}$ Department of Physics, Chaudhary Charan Singh University, Meerut 250004, India \\ ${ }^{2}$ Department of Physics, M.M.H. (PG) College, Ghaziabad 201001, India \\ ${ }^{3}$ Department of Chemistry, University of Puerto Rico, Mayaguez, PR 00681-9000, USA \\ Correspondence should be addressed to Beer Pal Singh; drbeerpal@gmail.com
}

Received 22 July 2015; Revised 24 January 2016; Accepted 27 January 2016

Academic Editor: Michael A. Fiddy

Copyright (C) 2016 Beer Pal Singh et al. This is an open access article distributed under the Creative Commons Attribution License, which permits unrestricted use, distribution, and reproduction in any medium, provided the original work is properly cited.

\begin{abstract}
The strategy and technique exploited in the synthesis of nanostructure materials have an explicit effect on the nucleation, growth, and properties of product materials. Nanoparticles of zinc sulfide ( $\mathrm{ZnS}$ ) have been synthesized by new infrared radiation (IR) assisted and Stokes' law based controlled bottom-up approach without using any capping agent and stirring. IR has been used for heating the reaction surface designed in accordance with the well-known Stokes law for a free body falling in a quiescent fluid for the synthesis of $\mathrm{ZnS}$ nanoparticles. The desired concentration of aqueous solutions of zinc nitrate $\left(\mathrm{Zn}\left(\mathrm{NO}_{3}\right)_{2} \cdot 4 \mathrm{H}_{2} \mathrm{O}\right)$ and thioacetamide $\left(\mathrm{CH}_{3} \mathrm{CSNH}_{2}\right)$ was reacted in a controlled manner by IR radiation heating at the reaction area (top layer of reactants solution) of the solution which results in the formation of $\mathrm{ZnS}$ nanoparticles at ambient conditions following Stokes' law for a free body falling in a quiescent fluid. The phase, crystal structure, and particle size of as-synthesized nanoparticles were studied by $\mathrm{X}$-ray diffraction (XRD). The optical properties of as-synthesized $\mathrm{ZnS}$ nanoparticles were studied by means of optical absorption spectroscopic measurements. The optical energy band gap and the nature of transition have been studied using the well-known Tauc relation with the help of absorption spectra of as-synthesized $\mathrm{ZnS}$ nanoparticles.
\end{abstract}

\section{Introduction}

The discovery and advancement in the new experimental techniques for the synthesis of functional materials at nanodimensions provide opportunities for the development of new and exciting research in nanostructure materials. The behavior of materials at the nanoscale can be exceptionally different from those at a larger scale and result in the deviation of device performance. As the dimensions of a material are reduced from a large size, initially the properties remain the same, then small changes occur, and finally when the sizes are below $\sim 100 \mathrm{~nm}$, remarkable changes in properties can take place. Therefore, there are endless possibilities for improved performance of devices, structures, and materials that can be realized by understanding the behavior and phenomena at nanoscale. Nanoparticle size confers unique size, shape, and orientation dependent properties such as surface plasmon resonance (SPR) in some metal particles, quantum confinement in semiconductor quantum dots, and superparamagnetism in magnetic materials. There are many examples of macroscopic manifestation of materials properties in semiconductors due to nanosized effects: more surface area (surface energy) to speed up almost all physical and manufacturing process [1]; optical emission tunability of semiconductor quantum dots [2]; enhancement of optical band gap. Because nanoparticles form a bridge between bulk materials and molecular structures, they are of immense scientific interest.

The control of exact size, shape, and orientation is still a great challenge in the synthesis of nanostructure materials using a bottom-up approach (chemical methods). The bottom-up approach is typically better and more reliable for mass production due to its ease, cost effectiveness, and purity. Among the "bottom-up approaches," coprecipitation is a most common and widely used method for preparation of 
nanoparticles. It is a simple, cost-effective and high yielding method. Precipitation reaction occurs when a cation and an anion of two aqueous solutions react in accordance to their solubility rules to form an ionic insoluble solid known as a precipitate in the solution where the reaction is taking place. It is possible by using the coprecipitation method to change the shape, size, and composition of the synthesized product with high reproducibility. The reaction conditions such as solution molarity and $\mathrm{pH}$, rate and manner of addition of the precipitator agent, and stirring time and temperature play a very important role to achieve the desired size, shape, and orientation of the final product. Recently, we have devised an entirely new IR assisted controlled method for the synthesis of CdS nanoparticles by means of a kinetic approach using the well-known Stokes' law for a free body falling in a quiescent fluid [3]. The reaction is controlled by means of IR heating only at the surface of the reactants and the successive synthesis of nanoparticles was governed by Stokes' law. The detailed description of the method is given elsewhere [3].

Zinc sulfide (ZnS) is a well-known II-VI semiconductor. It has attracted much research interest due to its potential applications in many solid state devices including lightemitting diodes (LEDs), electroluminescence, flat panel displays, infrared windows, sensors, lasers, and biodevices. ZnS has two commonly available allotropes: one with a cubic (zinc blende) structure and another one with a hexagonal (wurtzite) structure. The cubic form is the stable low-temperature phase, while hexagonal form is the hightemperature polymorph which forms at around $1296 \mathrm{~K}$ [4]. The band structure of a solid illustrates ranges of energy where an electron is "forbidden" or "allowed" and it determines important electronic and optical properties of the material. The optical spectra of a semiconducting material are related to its band structure, dispersion, nature, and probabilities of interband optical transitions. The wurtzite phase of $\mathrm{ZnS}$ has a relatively higher optical band gap $(3.77 \mathrm{eV})$ [5] than the zinc blende structure $(3.72 \mathrm{eV})[6]$; this results in distinct optical properties of the respective zinc blende and wurtzite phase [7].

A survey reveals that a large number of techniques for preparing $\mathrm{ZnS}$ nanoparticles have been applied by different workers such as solid state reaction [8], chemical methods [9-16], ball milling [17], coordination chemistry method [18], reverse micelle method [19], microwave assisted method [2023], and laser assisted method [24, 25]. Infrared-assisted ecofriendly green chemistry based methods have been employed in organic chemistry [26-29] but the infrared-assisted synthesis of inorganic nanoparticles has not been unveiled. Inspired from this, recently, we have synthesized IR assisted CdS nanoparticles by means of a kinetic approach using the well-known Stokes law without using any surfactant, capping agent, or stirring [3]. In this present research work, we have synthesized ZnS nanoparticles by a simple controlled chemical coprecipitation method using IR radiation heating by means of a kinetic approach using the well-known Stokes law for a free body falling in a quiescent and viscous fluid without using any surfactant or stirring during the reaction.

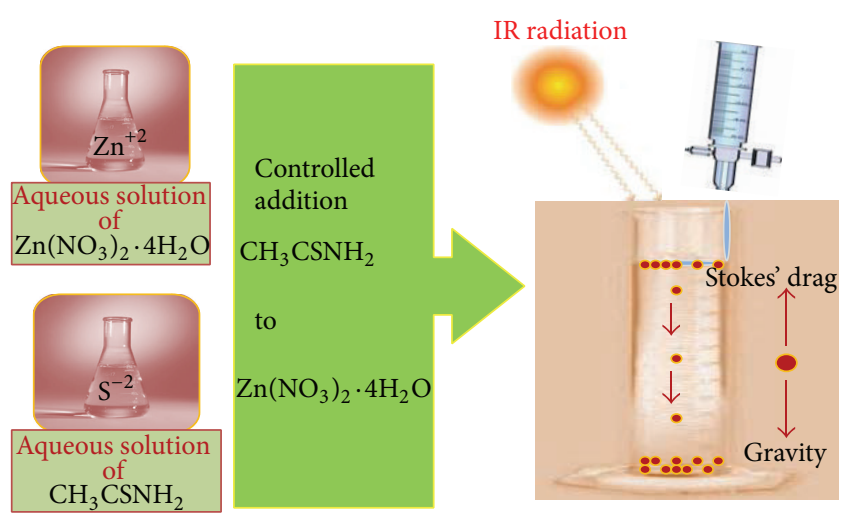

FIGURE 1: Schematic illustration of controlled IR assisted chemical precipitation method based on Stokes' law for a free body falling in a quiescent and viscous fluid as used for synthesis of $\mathrm{ZnS}$ nanoparticles.

\section{Materials and Experimental Details}

$\mathrm{ZnS}$ nanoparticles were prepared through an experiment designed in accordance with Stokes' law for a free body falling in a quiescent fluid using IR radiation lamp as a heating source. The experiment mainly consists of a long beaker $(\sim 30 \mathrm{~cm})$ for free falling of particles, IR radiation lamp (commercial) for heating the upper surface of the solution, and burette to add the anion (sulfur ions) solution to the cation (zinc ions) solution in a controlled manner. All the chemicals are of analytic grade and used without further purification. The entire process is carried out in distilled water for its inherent benefit of being straightforward and environmentally friendly. Nanoparticles of $\mathrm{ZnS}$ were made by controlled reaction through a chemical precipitation method using an aqueous solution of zinc nitrate $\left(\mathrm{Zn}\left(\mathrm{NO}_{3}\right)_{2} \cdot 4 \mathrm{H}_{2} \mathrm{O}\right)$ and thioacetamide $\left(\mathrm{CH}_{3} \mathrm{CSNH}_{2}\right)$. The reaction was controlled with the help of a drop-by-drop addition of the aqueous solution of thioacetamide $\left(\mathrm{CH}_{3} \mathrm{CSNH}_{2}\right)$ into the aqueous solution of zinc nitrate $\left(\mathrm{Zn}\left(\mathrm{NO}_{3}\right)_{2} \cdot 4 \mathrm{H}_{2} \mathrm{O}\right)$ in the presence of continuous IR lamp heating on the top as shown in schematic diagram Figure 1. Firstly, the stock aqueous solutions of zinc nitrate $\left(\mathrm{Zn}\left(\mathrm{NO}_{3}\right)_{2} \cdot 4 \mathrm{H}_{2} \mathrm{O}\right)(0.2 \mathrm{M})$ and thioacetamide $\left(\mathrm{CH}_{3} \mathrm{CSNH}_{2}\right)(0.2 \mathrm{M})$ were made. The stock solution of zinc nitrate and thioacetamide was transferred to a long beaker $(\sim 30 \mathrm{~cm})$ and a microburette, respectively. The aqueous solution of thioacetamide was added in a controlled manner to the solution of zinc nitrate using a burette drop-by-drop on a beaker wall in the presence of continuous IR lamp heating on the top of the beaker as illustrated in Figure 1. A controlled precipitation reaction occurs on the top contact layer of solutions when the cation and anion aqueous solutions react on the upper surface (top layer) in the presence of IR radiation [3] to form an insoluble $\mathrm{ZnS}$ solid as a precipitate in the solution. As a result, the nanoparticles of $\mathrm{ZnS}$ float down to the bottom of the long beaker following Stokes' law. The process is continuous as synthesis starts at the top and moves downward under gravity in the quiescent and viscous solution according to Stokes' law. The rate of reaction is very slow so the process of formation of nanoparticles takes a 


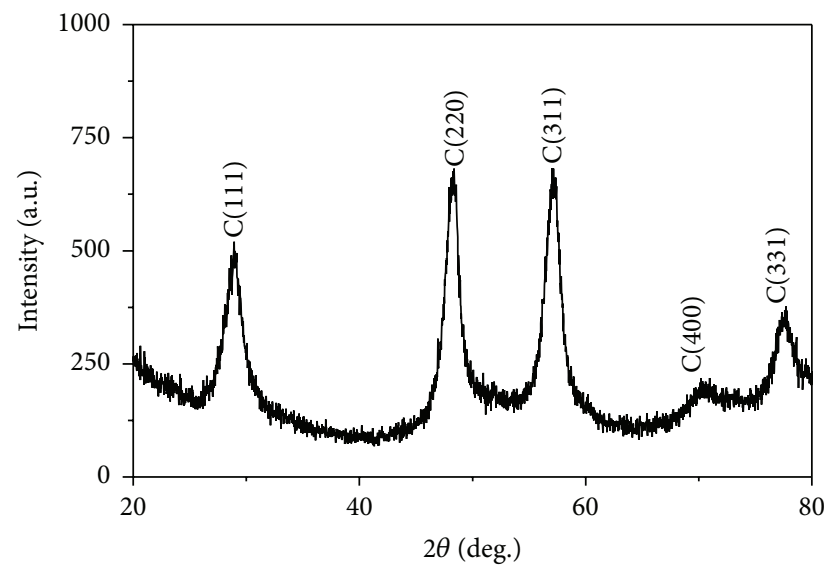

FIGURE 2: XRD pattern of as-prepared ZnS nanoparticles.

few days and after completing the process the nanoparticles accumulate at the bottom of beaker in the form of a precipitate. Finally, the precipitate was decanted and dried so as to have a final product for further characterization.

The phase, crystallinity, and particle size of the as-prepared ZnS nanoparticles were characterized by X-ray powder diffraction (XRD) using a Bruker, D8 Advance X-ray diffractometer with $\mathrm{CuK}_{\alpha}$ radiation $(1.54 \AA)$ over the $2 \theta$ range $20-80^{\circ}$. The optical characterization was made using doublebeam UV-Vis Spectrophotometer (Model: Hitachi U-3400). In this model a prism/grating double monochromatic system is used. The lenses which were conventionally used in the monochromatic system have all been replaced with mirrors. The $\mathrm{PbS}$ detector converges the light beam with a toroidal mirror located below the photomultiplier. Absorption spectra in the spectral range $300-500 \mathrm{~nm}$ were used to study the optical properties of the $\mathrm{ZnS}$ nanoparticles.

\section{Results and Discussions}

3.1. X-Ray Diffraction (XRD) Studies. The fact that X-rays have a wavelength of the order of angstroms, which is suitable for interatomic distances in solids, makes this technique an excellent instrument to investigate the phase and crystalline structure of the materials. Figure 2 shows the XRD pattern of $\mathrm{ZnS}$ nanoparticles at room temperature. From this figure, it is clear that as-prepared $\mathrm{ZnS}$ nanoparticles have a high degree of crystallographic orientation. The peak broadening in the $\mathrm{XRD}$ pattern of $\mathrm{ZnS}$ clearly indicates the formation of $\mathrm{ZnS}$ nanocrystals of small size. In Figure 2, the higher intensity peaks at around $28.95^{\circ}, 48.29^{\circ}$, and $57.15^{\circ}$ reveal a cubic (zinc blende) lattice structure of $\mathrm{ZnS}$, which were consistent with the literature data of JCPDS card number 05-0566. These peaks could be easily assigned to the planes (111), (220), and (311), respectively, of the cubic phase [30]. Two low intensity peaks at 70.62 and 77.55 are also the characteristics of cubic (400) and (311) planes, respectively. From the XRD patterns, it is clear that the $\mathrm{ZnS}$ nanoparticles are polycrystalline in nature having a cubic (zinc blende) lattice structure. The $d_{h k l}$ values (distances between successive lattice planes) of the
TABLE 1: Lattice constants as-prepared ZnS nanocrystals.

\begin{tabular}{lcccc}
\hline S. number & Plane $(h k l)$ & $d_{h k l}(\AA)$ & $a(\AA)$ & $a_{\text {average }}(\AA)$ \\
\hline$(1)$ & $(111)$ & 3.08 & 5.33 & \\
$(2)$ & $(220)$ & 1.88 & 5.32 & \\
$(3)$ & $(311)$ & 1.61 & 5.33 & 5.33 \\
$(4)$ & $(400)$ & 1.33 & 5.32 & \\
$(5)$ & $(331)$ & 1.23 & 5.36 & \\
\hline
\end{tabular}

as-prepared $\mathrm{ZnS}$ nanocrystals were calculated from wellknown Bragg relation:

$$
2 d_{h k l} \sin \theta=n \lambda,
$$

where $\lambda$ is the wavelength of $\mathrm{X}$-ray radiation source, $\theta$ is the Bragg's angle of incidence, and the integer $n$ is the order of the corresponding reflection. The lattice constant " $a$ " of the $\mathrm{ZnS}$ crystallites was determined from the XRD patterns (Figure 2) using the following formula:

$$
d_{h k l}=\frac{a}{\sqrt{h^{2}+k^{2}+l^{2}}} .
$$

Lattice constants of as-prepared $\mathrm{ZnS}$ nanocrystals are given in Table 1. The value of lattice constant " $a$ " of as-prepared $\mathrm{ZnS}$ nanocrystals is in good agreement with the standard value for ZnS cubic (zinc blende) lattice structure phase ( $a=5.398 \AA$ ).

It is well-known that XRD line broadening is influenced by the crystallite size and the internal strain present in the sample. The crystallite size $(D)$ and internal strain were obtained by fitting the following Williamson-Hall equation [31] using XRD data of as-prepared $\mathrm{ZnS}$ nanoparticles:

$$
B \cos \theta=\frac{K \lambda}{D}+2 \epsilon \sin \theta
$$

where $B$ is the full width half maximum (FWHM) of a particular diffraction peak due to strain and size effect in radians, $\theta$ is the Bragg angle and $K$ is a constant equal to 0.9, $\lambda$ is the wavelength used $(\lambda=1.54 \AA$ $), D$ is the coherent scattering length (crystallite size), and $\epsilon$ is the internal strain (in $\%)$. The high intense dominating reflection peaks of the XRD patterns (Figure 2) were used in the line broadening analysis of the sample. Figure 3 shows the Williamson-Hall plot $(\sin \theta$ versus $B \cos \theta$ ) fitted to a straight line. The crystallite size $(D)$ is given by intercept of the straight line and using the Williamson-Hall equation. The crystallite size $(D)$ of asprepared $\mathrm{ZnS}$ nanoparticles calculated in the above manner is found to be $2.77 \mathrm{~nm}$.

The crystallite size $(D)$ was also calculated from Scherrer formula [32]:

$$
D=\frac{K \lambda}{B \cos \theta} .
$$

The peak broadening at lower angles is more meaningful for the calculation of particle size; therefore the size of $\mathrm{ZnS}$ nanoparticles was calculated using the high intensity peak (220) at the $2 \theta$ value $48.29^{\circ}$. The calculated particle size is found to be $4.39 \mathrm{~nm}$. 


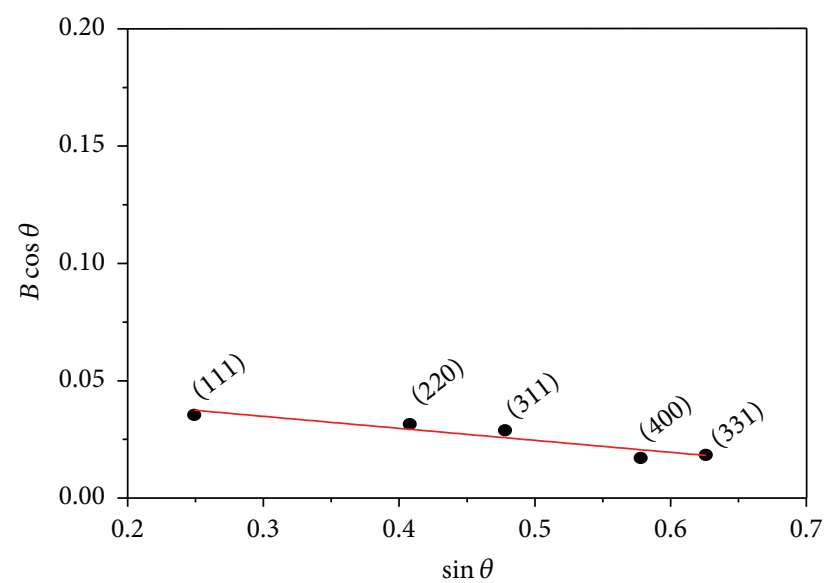

- Experimental data

- Linear fit

Figure 3: Williamson-Hall plot ( $\sin \theta$ versus $B \cos \theta$ ) for $Z n S$ Nanoparticles (fitted to a straight line).

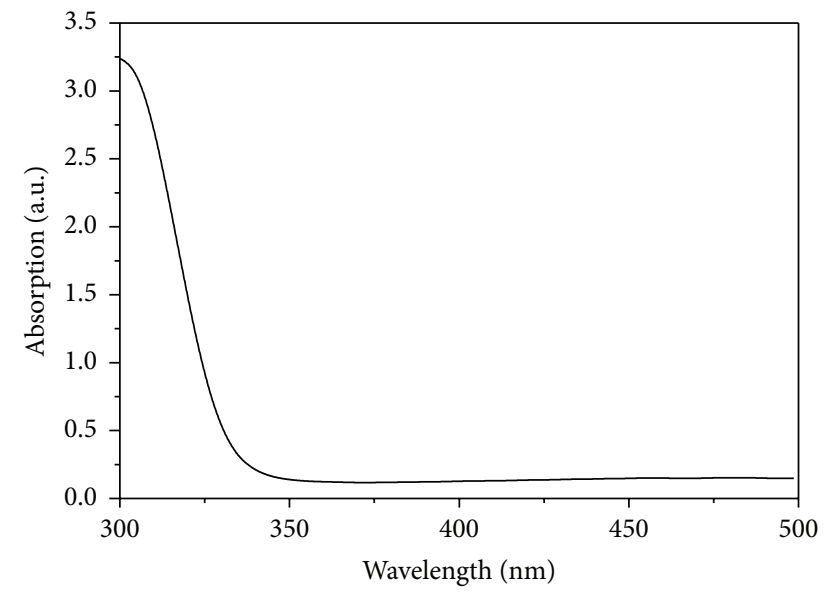

FIgURE 4: Absorption spectra of as-prepared $\mathrm{ZnS}$ nanocrystals.

3.2. Optical Properties. Semiconductors behave very differently, in comparison with bulk, when their crystal sizes are reduced down to the order of a few nanometers. One of the most significant characteristic in these materials is the variation of the band gap when the sizes of nanocrystal decrease below the Bohr exciton radius $\left(a_{\mathrm{B}}\right)$. The optical absorption spectroscopic technique is used to study the electronic band structure of semiconductors and metals for determination of their optical properties. Optical absorption spectrum of $\mathrm{ZnS}$ samples was measured at room temperature using a Hitachi U 3400 UV-Vis Spectrophotometer. The asprepared $\mathrm{ZnS}$ nanopowder that was suspended in glycerol using a magnetic stirrer and the optical absorption spectra was recorded at room temperature in the wavelength range $300-500 \mathrm{~nm}$ as shown in Figure 4.

The absorption spectra show that the optical absorption coefficient increases sharply at lower wavelength, which is a sign of the narrower size distribution of the $\mathrm{ZnS}$ nanoparticles. Blue shifting of the absorption peak (absorption edge

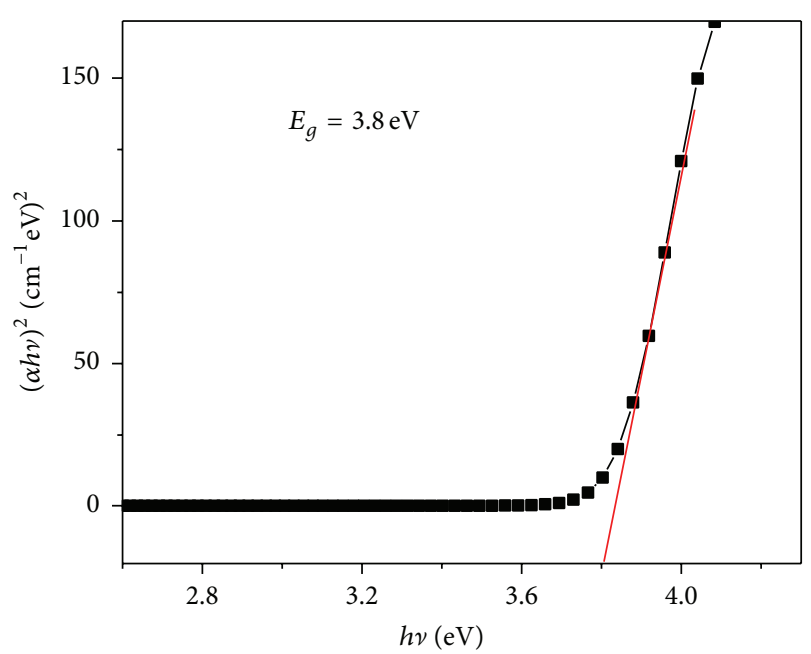

Figure 5: Plot of $(\alpha h \nu)^{2}$ versus $h \nu$ for determination of optical band gap of $\mathrm{ZnS}$ nanoparticles.

at about $325 \mathrm{~nm}$ ) is due to quantum confinement of the excitons present in the sample resulting in a more discrete energy of the spectrum of individual nanoparticles. Optical excitation of electrons across the band gap is a strongly allowed transition, and this causes a sharp increase in the absorbance at the wavelength corresponding to the optical energy band gap.

The fundamental absorption, which corresponds to electron excitation from the valance band to conduction band, can be used to determine the value of the optical band gap of the $\mathrm{ZnS}$ nanoparticles. The optical band gap of as-prepared $\mathrm{ZnS}$ nanoparticles was determined using absorption spectra by the following Tauc relation [33]:

$$
\alpha h v=A\left(h v-E_{g}\right)^{n},
$$

where $\alpha$ is the absorption coefficient, $h \nu$ is photon energy, $A$ is a constant, $E_{g}$ is the optical energy band gap of the material, exponent $n$ depends on the nature of optical transition, and $n=1 / 2$ is for an allowed direct transition. A plot $(\alpha h \nu)^{2}$ versus photon energy $(h v)$ is shown in Figure 5, and when extrapolated, the linear portion at zero absorption axis provides the value of the optical energy gap as $3.8 \mathrm{eV}$. The obtained band gap value of the sample is blue shifted as compared to the bulk band gap value and is evidence of quantum confinement in the as-prepared sample of $\mathrm{ZnS}$ nanoparticles as attributed due to the nanocrystalline nature of ZnS particles. The nature of the optical band gap (transition) of the as-prepared $\mathrm{ZnS}$ nanoparticles was studied by using logarithm form of Tauc's equation as follows:

$$
\ln (\alpha h v)=\ln A+n \ln \left(h v-E_{g}\right) .
$$

The value of the optical band gap $\left(E_{g}\right)$ of the as-prepared $\mathrm{ZnS}$ nanoparticles was used to study the nature of band gap. The slope of linear region of the plot $\ln (\alpha h v)$ versus $\ln (h v-$ $E_{g}$ ) as shown in Figure 6 provides " $n$ " value $\sim 1 / 2$, which indicated an allowed direct transition in the as-prepared $\mathrm{ZnS}$ nanoparticles. 


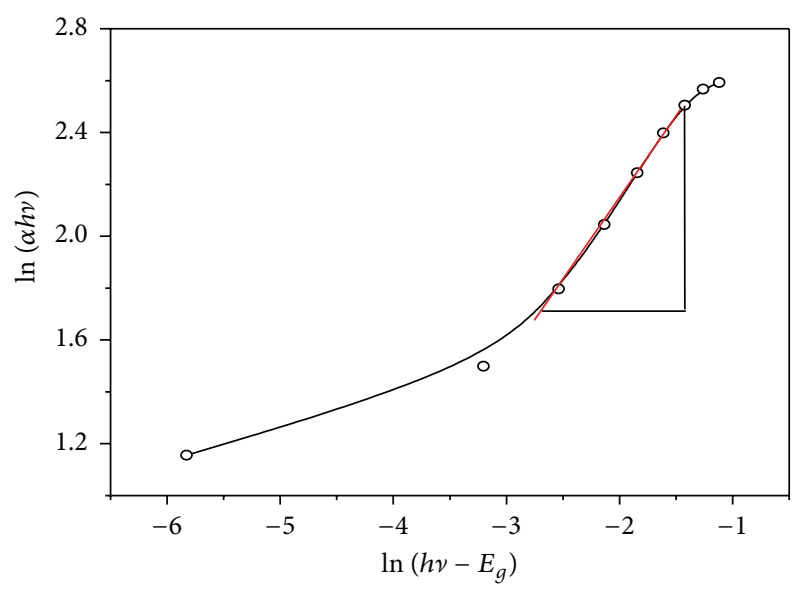

Figure 6: Plot of $\ln (\alpha h v)$ versus $\ln \left(h v-E_{g}\right)$ of as-prepared $\mathrm{ZnS}$ nanoparticles. The slope $(n) \sim 0.5$ shows the direct type transition.

The average particle size of $\mathrm{ZnS}$ nanoparticles has also been determined by using the mathematical model of "effective mass approximation." According to "effective mass approximation" (EMA) for spherical clusters [34, 35], the quantum confinement equation is given as

$$
\begin{aligned}
E_{g}^{\text {nano }}-E_{g}^{\text {bulk }}= & \Delta E \\
= & \frac{h^{2}}{8 r^{2}}\left[\frac{1}{m_{e}^{*}}+\frac{1}{m_{h}^{*}}\right]-\frac{1.8 e^{2}}{4 \pi \varepsilon \varepsilon_{o} r} \\
& -0.248 E_{\mathrm{RY}}^{*},
\end{aligned}
$$

where $E_{g}^{\text {nano }}$ and $E_{g}^{\text {bulk }}$ are the optical band gap energy for nanoparticles and bulk of the same material, respectively. $\Delta E$ represents the difference (enhancement) in the optical band energy, $r$ is the radius of a nanoparticle, $m_{e}^{*}$ and $m_{h}^{*}$ are the effective masses of an electron and a hole in units of free electron mass $\left(m_{o}\right), e$ is the electronic charge, $\varepsilon$ is the dielectric constant, $\varepsilon_{o}$ is the permittivity of free space, and $E_{\mathrm{RY}}^{*}$ is the effective Rydberg energy. The contribution of Coulomb (second term) and Rydberg (third term) terms is much smaller than the first confinement term [36] due to the relatively high value of dielectric constant for semiconducting materials. By omitting these terms, the equation for $\Delta E$ is reduced as follows:

$$
\Delta E=\frac{h^{2}}{8 r^{2}}\left[\frac{1}{m_{e}^{*}}+\frac{1}{m_{h}^{*}}\right]
$$

The values of the effective mass of an electron and hole for ZnS are $m_{e}^{*}=0.41 m_{e}$ and $m_{h}^{*}=0.61 m_{h}$ [37]. The average particle size of as-prepared $\mathrm{ZnS}$ nanoparticles was also calculated using the above described mathematical model of effective mass approximation and found to be $2.6 \mathrm{~nm}$, which is in good agreement with the particle size calculated by W-H method using XRD parameters.

\section{Conclusions}

ZnS nanoparticles were effectively synthesized by an infrared (IR) radiation assisted and Stokes' law based new controlled bottom-up approach without using any capping agent or stirring. The reaction is controlled by the IR radiation surface heating and consequently the synthesis mechanism is based on the physics of the well-known Stokes' law for a free body falling in a quiescent and viscous fluid. The structural and optical characterization of the as-prepared $\mathrm{ZnS}$ nanoparticles confirms the nanosize formation. The XRD pattern also confirms that the $\mathrm{ZnS}$ nanoparticles are polycrystalline in nature having a cubic (zinc blende) lattice structure. The absorption spectra show the quantum confinement effect which was used in the studies of the optical properties of the as-synthesized $\mathrm{ZnS}$ nanoparticles. The initial results of this study show the importance of their synthesis approach and further work to expose the control of size, shape, and orientation of the nanoparticles by optimizing the process parameters is in progress.

\section{Conflict of Interests}

The authors declare that there is no conflict of interests regarding the publication of this paper.

\section{References}

[1] A. Henkel, O. Schubert, A. Plech, and C. Sönnichsen, "Growth kinetic of a rod-shaped metal nanocrystal," The Journal of Physical Chemistry C, vol. 113, no. 24, pp. 10390-10394, 2009.

[2] A. P. Alivisatos, "Semiconductor clusters, nanocrystals, and quantum dots," Science, vol. 271, no. 5251, pp. 933-937, 1996.

[3] B. P. Singh, S. Tyagi, and R. Kumar, "Gradation of nanoparticle size by stokes' law: a new approach for synthesis of CdS nanoparticles," International Journal of Advanced Applied Physics Research, vol. 2, no. 1, pp. 31-36, 2015.

[4] S. Z. Karazhanov, P. Ravindran, A. Kjekshus, H. Fjellvåg, and B. G. Svensson, "Electronic structure and optical properties of $\mathrm{ZnX}(\mathrm{X}=\mathrm{O}, \mathrm{S}, \mathrm{Se}, \mathrm{Te})$ : a density functional study," Physical Review B, vol. 75, no. 15, Article ID 155104, 2007.

[5] C.-Y. Yeh, S.-H. Wei, and A. Zunger, "Relationships between the band gaps of the zinc-blende and wurtzite modifications of semiconductors," Physical Review B, vol. 50, no. 4, pp. 27152718, 1994.

[6] S. Adachi, Ed., Optical Constants of Crystalline and Amorphous Semiconductors: Numerical Data and Graphical Information, Kluwer Academic, Boston, Mass, USA, 1999.

[7] V. L. Gayou, B. Salazar-Hernández, R. D. Macuil, G. Zavala, P. Santiago, and A. I. Oliva, "Structural studies of ZnS nanoparticles by high resolution transmission electron microscopy," Journal of Nano Research, vol. 9, pp. 125-132, 2010.

[8] L. P. Wang and G. Y. Hong, "New preparation of zinc sulfide nanoparticles by solid-state method at low temperature," Materials Research Bulletin, vol. 35, no. 5, pp. 695-701, 2000.

[9] S. W. Lu, B. I. Lee, Z. L. Wang et al., "Synthesis and photoluminescence enhancement of $\mathrm{Mn}^{2+}$-doped $\mathrm{ZnS}$ nanocrystals," Journal of Luminescence, vol. 92, no. 1-2, pp. 73-78, 2000. 
[10] S. Wageh, Z. S. Ling, and X. Xu-Rong, "Growth and optical properties of colloidal ZnS nanoparticles," Journal of Crystal Growth, vol. 255, no. 3-4, pp. 332-337, 2003.

[11] P. Yang, M. Lü, D. Xü et al., "Strong green luminescence of Ni2+doped ZnS nanocrystals," Applied Physics A, vol. 74, no. 2, pp. 257-259, 2002.

[12] C. S. Pathak, D. D. Mishra, V. Agarwala, and M. K. Mandal, "Blue light emission from barium doped zinc sulfide nanoparticles," Ceramics International, vol. 38, no. 7, pp. 5497-5500, 2012.

[13] B. P. Singh, S. P. Singh, S. Vishnoi, and R. Kumar, "Synthesis and optical properties of aggregated nanospheres of ZnS nanoparticles," Journal of Optoelectronics and Biomedical Materials, vol. 4, no. 2, pp. 29-33, 2012.

[14] S. P. Singh, B. P. Singh, S. Vishnoi, and R. Kumar, "Structural and optical characterization of Zinc Sulfide nanocrystals in a PVA matrix," International Journal of Nanotechnology and Applications, vol. 6, no. 3, pp. 149-157, 2012.

[15] J. Kaur, M. Sharma, and O. P. Pandey, "Photoluminescence and photocatalytic studies of metal ions ( $\mathrm{Mn}$ and $\mathrm{Ni}$ ) doped $\mathrm{ZnS}$ nanoparticles," Optical Materials, vol. 47, pp. 7-17, 2015.

[16] R. K. Chandrakar, R. Baghel, V. Chandra, and B. Chandra, "Synthesis, characterization and photoluminescence studies of undoped ZnS nanoparticles," Superlattices and Microstructures, vol. 84, pp. 132-143, 2015.

[17] C. S. Pathak, D. D. Mishra, V. Agarwala, and M. K. Mandal, "Optical properties of ZnS nanoparticles prepared by high energy ball milling," Materials Science in Semiconductor Processing, vol. 16, no. 2, pp. 525-529, 2013.

[18] M. W. Wang, L. D. Sun, X. F. Fu, C. S. Liao, and C. H. Yan, "Synthesis and optical properties of $\mathrm{ZnS}: \mathrm{Cu}(\mathrm{II})$ nanoparticles," Solid State Communications, vol. 115, no. 9, pp. 493-496, 2000.

[19] L. X. Cao, J. H. Zhang, S. L. Ren, and S. H. Huang, "Luminescence enhancement of core-shell ZnS:Mn/ZnS nanoparticles," Applied Physics Letters, vol. 80, no. 23, pp. 4300-4302, 2002.

[20] F. A. La Porta, M. M. Ferrer, Y. V. B. de Santana et al., "Synthesis of wurtzite $\mathrm{ZnS}$ nanoparticles using the microwave assisted solvothermal method," Journal of Alloys and Compounds, vol. 556, pp. 153-159, 2013.

[21] Y. Zhao, J.-M. Hong, and J.-J. Zhu, "Microwave-assisted selfassembled ZnS nanoballs," Journal of Crystal Growth, vol. 270, no. 3-4, pp. 438-445, 2004.

[22] X. Yan, E. Michael, S. Komarneni, J. R. Brownson, and Z.-F. Yan, "Microwave- and conventional-hydrothermal synthesis of CuS, $\mathrm{SnS}$ and ZnS: optical properties," Ceramics International, vol. 39, no. 5, pp. 4757-4763, 2013.

[23] J. Zhang, Q. Chen, W. Zhang et al., "Microwave-assisted aqueous synthesis of transition metal ions doped $\mathrm{ZnSe/ZnS} \mathrm{core/}$ shell quantum dots with tunable white-light emission," Applied Surface Science, vol. 351, pp. 655-661, 2015.

[24] D. C. Onwudiwe, T. P. J. Krüger, A. Jordaan, and C. A. Strydom, "Laser-assisted synthesis, and structural and thermal properties of ZnS nanoparticles stabilised in polyvinylpyrrolidone," Applied Surface Science, vol. 321, pp. 197-204, 2014.

[25] D. C. Onwudiwe, T. P. J. Krüger, and C. A. Strydom, "Laser assisted solid state reaction for the synthesis of $\mathrm{ZnS}$ and CdS nanoparticles from metal xanthate," Materials Letters, vol. 116, pp. 154-159, 2014.

[26] M. O. Noguez, V. Marcelino, H. Rodríguez et al., "Infrared assisted production of 3,4-dihydro-2(1H)-pyridones in solventfree conditions," International Journal of Molecular Sciences, vol. 12, no. 12, pp. 2641-2649, 2011.
[27] D. Wang and Y. Li, "Bimetallic nanocrystals: liquid-phase synthesis and catalytic applications," Advanced Materials, vol. 23, no. 9, pp. 1044-1060, 2011.

[28] V. Polshettiwar and R. S. Varma, "Green chemistry by nanocatalysis," Green Chemistry, vol. 12, no. 5, pp. 743-754, 2010.

[29] G. Penieres-Carrillo, J. G. García-Estrada, J. L. GutiérrezRamírez, and C. Alvarez-Toledano, "Infrared-assisted ecofriendly selective synthesis of diindolylmethanes," Green Chemistry, vol. 5, no. 3, pp. 337-339, 2003.

[30] R. Sahraei, G. M. Aval, A. Baghizadeh, M. Lamehi-Rachti, A. Goudarzi, and M. H. M. Ara, "Investigation of the effect of temperature on growth mechanism of nanocrystalline $\mathrm{ZnS}$ thin films," Materials Letters, vol. 62, no. 28, pp. 4345-4347, 2008.

[31] O. M. Lemine, "Microstructural characterisation of $\alpha-\mathrm{Fe}_{2} \mathrm{O}_{3}$ nanoparticles using, XRD line profiles analysis, FE-SEM and FT-IR," Superlattices and Microstructures, vol. 45, no. 6, pp. 576582, 2009.

[32] H. P. Klug and L. E. Alexander, X-Ray Diffraction Procedures for Polycrystalline and Amorphous Materials, John Wiley \& Sons, New York, NY, USA, 2nd edition, 1954.

[33] J. Tauc, Amorphous and Liquid Semiconductors, Plenum Press, New York, NY, USA, 1974.

[34] A. L. Efros and A. L. Efros, "Interband absorption of light in a semiconductor sphere," Soviet Physics Semiconductors, vol. 16, no. 7, pp. 772-775, 1982.

[35] L. E. Brus, "Electronic wave functions in semiconductor clusters: experiment and theory," Journal of Physical Chemistry, vol. 90, no. 12, pp. 2555-2560, 1986.

[36] Y. Kayanuma, "Quantum-size effects of interacting electrons and holes in semiconductor microcrystals with spherical shape," Physical Review B, vol. 38, no. 14, pp. 9797-9805, 1988.

[37] P. E. Lippens and M. Lannoo, "Optical properties of II-VI semiconductor nanocrystals," Semiconductor Science and Technology, vol. 6, pp. A157-A160, 1991. 


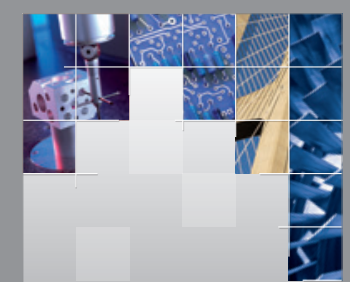

\section{Enfincering}
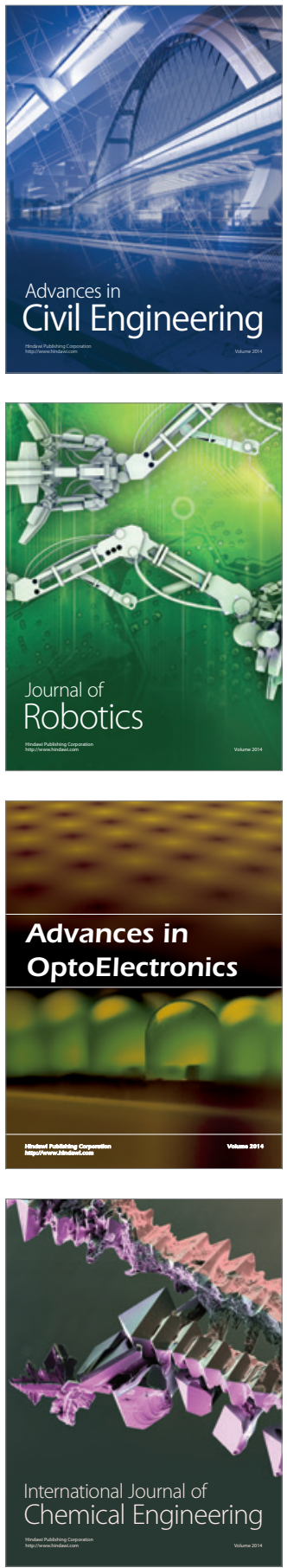

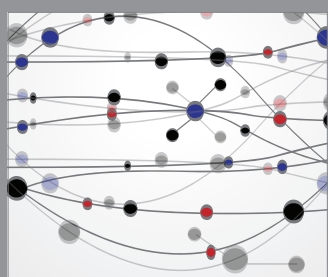

The Scientific World Journal

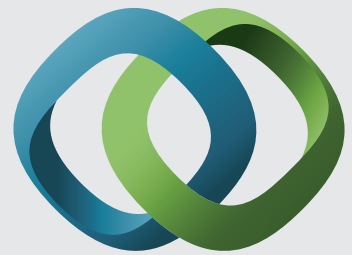

\section{Hindawi}

Submit your manuscripts at

http://www.hindawi.com
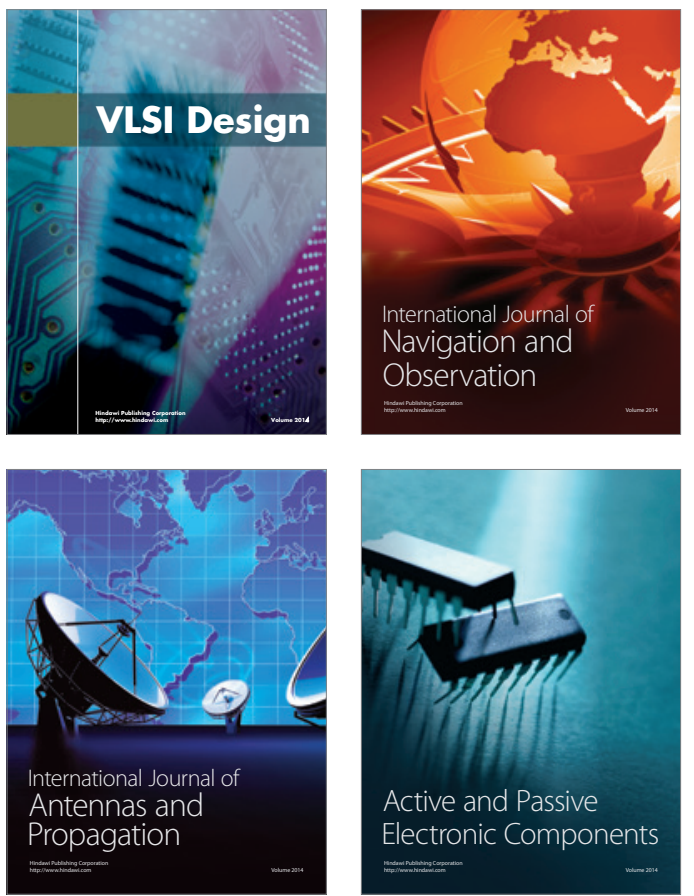
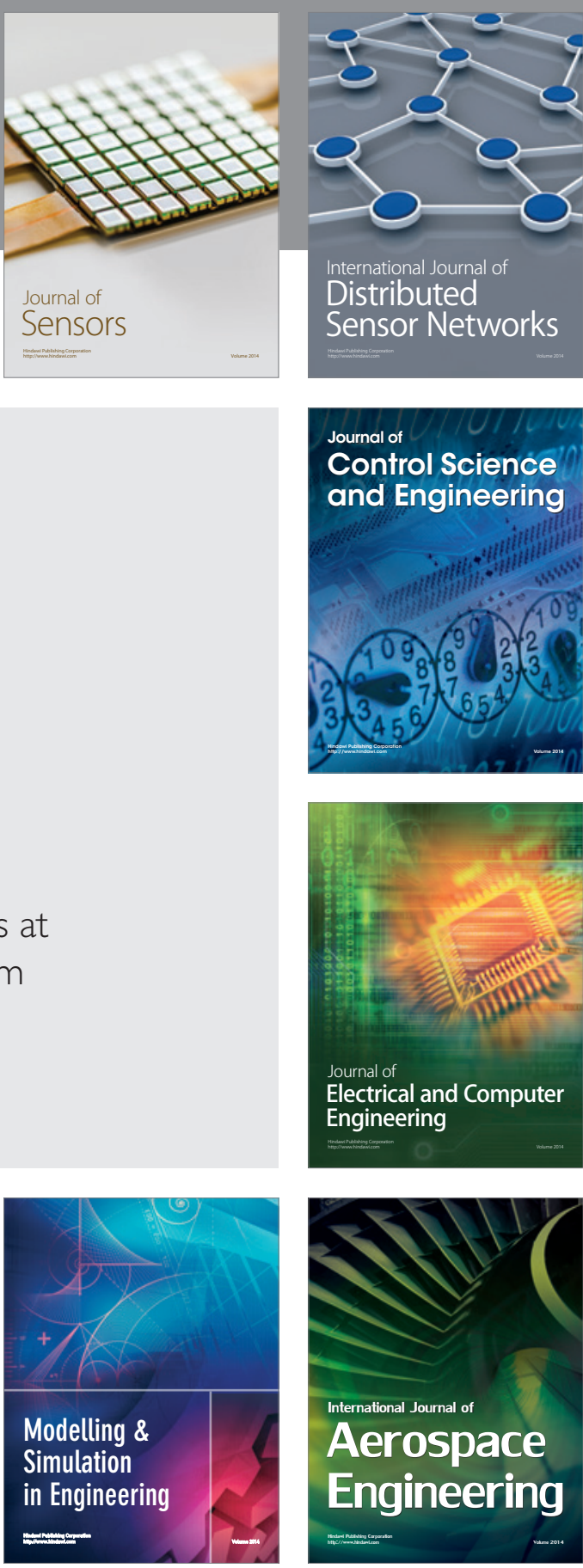

International Journal of

Distributed

Sensor Networks

Journal of

Control Science

and Engineering
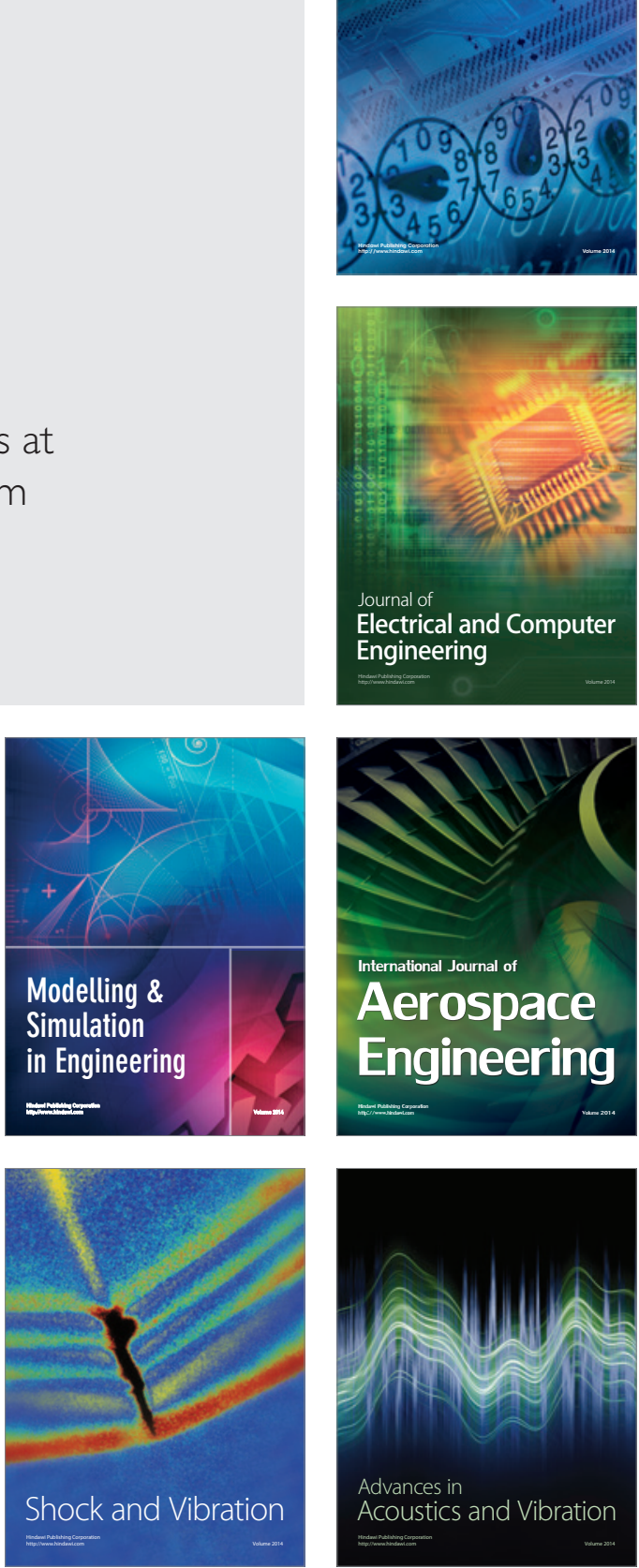